has started, since there is evidence that decalcification can be prevented but not reversed by oestrogen therapy. ${ }^{8}$ So though steroids for contraceptive purposes might be stopped about the age of 50, there may be a case for continuing them for other reasons, not least being the suppression of unpleasant menopausal symptoms and the promotion of the well-being that such treated women feel. After the menopause it is not usual to prescribe progestogens, and the oestrogen is given continuously either by implant or by mouth. Careful monitoring is of course essential in these patients, and it has to be said, as usual, that more research is needed-there have been recent reports of abnormalities in blood lipids ${ }^{9}$ and an increased susceptibility to gallstones ${ }^{10}$ in patients given postmenopausal oestrogens.

\footnotetext{
1 Garcia, C. R., Pincus, G. and Rock, J. (1958). American Fournal of Obstetric Gynecology, 75, 82 .

DeCosta, E. J. (1962). J.A.M.A. 181, 122

3 Potts, D. M., and Swyer, G. I. M. (1970). British Medical Bulletin, 26, 26.

Fuertes-de la Haba, A., Pelegrina, I., Bangdiwala, I. S. and HernandezCibes, J. J. (1973). Fournal Reproductive Medicine, 10, 3.

5 Royal College of General Practitioners, Oral Contraceptives and Health London, Pitman Medical, 1974.

6 Frommer, D. J. (1964). British Medical fournal, 2, 349.

7 Davies, M. E. (1964). Year Book of Obstetrics and Gynecology, ed. J. P. Greenhill Chicago. 339.

${ }^{8}$ Aitken, J. M., Hart, D. M., and Lindsay, R., British Medical Fournal, 1973,

Molitch, M. E., Oill, P., and Odell, W. D., fournal of the American Medical

Association, 1974, 227, 522.
10 Boston, Collaborative Drug Surveillance Programme, New England fournal of Medicine, 1974, 290, 15.
}

\section{Blind Children}

Most readers of the $B . M . \mathcal{F}$. have never seen xerophthalmiathe generic term for all the ophthalmic lesions of vitamin A deficiency-or will have recognized it only as an occasional accident of malnutrition. Since Bloch ${ }^{1}$ showed 50 years ago that the disease, then widespread among children in postwar Denmark, could be effectively and easily prevented by cod liver oil and dairy foods it has disappeared from all countries with adequate community medical and welfare services. The cause is now so well understood, while prevention and cure seem so straightforward, that the problem might appear to have no further medical interest.

Ten years ago McLaren ${ }^{2}$ estimated that approximately 20,000 children throughout the world go blind every year from xerophthalmia with keratomalacia. This seems to be an underestimate, for Venkataswamy ${ }^{3}$ has reported that in Madras State alone in 1961 some $9-10,000$ children under 4 years of age were blind owing to keratomalacia. The numbers are increasing with the increasing population of children, increasing poverty, and increasing pressure on food supplies. The disease is closely related to protein-calorie malnutrition, having its worst effects on young children between their first and fifth birthday. Typically it does not occur through simple dietary deficiency of vitamin A but as a complication of general malnutrition, diarrhoea, and the common infections of childhood. It is a part of the general picture of high morbidity and high mortality at weaning. Because it has a complex relationship with protein-calorie malnutrition and affects the poorest and most severely malnourished young children, it is often overlooked, for this most vulnerable group in the community is the least accessible to medical and welfare services.

The incidence of blindness gives little clue to the real incidence of deficiency, for the mortality from keratomalacia is high, and only a minority of children who are deficient in vitamin $\mathrm{A}$ and therefore at risk have xerosis of conjunctiva or cornea. The earliest clinical sign-night-blindness-is the most amenable to treatment. Blankhart, ${ }^{6}$ in a small longitudinal study, found that over a quarter of the children in some Indonesian villages passed through at least one incident of vitamin A deficiency as diagnosed by a simple test for night-blindness.

A disease affecting the sight and survival of masses of children living in poverty cannot be effectively treated by the qualified physician or ophthalmologist working in the outpatient clinic or hospital. The children are dead or blind before they are seen. This has been repeatedly emphasized by Mclaren and Oomen. ${ }^{2-5}$ Schemes for health and nutritional education, however well conceived, are too slow in action to save children who will certainly become blind this year; yet each of them could be saved by a few milligrams out of the tons of retinol synthesized by the pharmaceutical industry, or by some cheap supplement, regularly administered, prepared from readily available local sources of vegetable carotenoids, fish liver oils, or dairy foods.

The medical profession has a clear duty to look for xerophthalmia among the young children of Central and South America, Africa, and Asia, to teach paramedical staff and welfare workers to recognize and treat it, and to organize effective prophylaxis with cheapest available vitamin supplements. To promote measures of this kind which could help to prevent xerophthalmia and to co-ordinate activities and information, the Xerophthalmia Club has been formed under the chairmanship of Professor H. A. P. C. Oomen. ${ }^{7}$ Anybody interested in blind children should join this club.

1 Bloch, C. E., American Fournal of Diseases of Children, 1924, 27, 139 ${ }^{2}$ McLaren, D. S., Malnutrition and the Eye. New York and London, Academic Press, 1963.

Causes and Prevention of Blindness, ed. Michaelson, I. C., and Elaine R Berman, New York and London, Academic Press, 1972.

4 Oomen, H. A. P. C., MacLaren, D. S., and Escapini, H., Tropical and Geographical Medicine, 1964 16, 271.

5 McLaren, D. S., Oomen, H. A. P. C., and Escapini, H., Bulletin of the World Health Organization, 1966, 34, 357.

${ }^{6}$ Blankhart, D. M., Tropical and Geographical Medicine, 1967, 19, 144 Secretary, Dr. A. Pirie, Girton College, Cambridge.

\section{Active Chronic Hepatitis}

Active chronic hepatitis has in the past gone by a number of names including lupoid hepatitis, juvenile cirrhosis, and plasma cell hepatitis. The newer term embodies at least two of the essential features of the condition, namely a chronic progressive liver disorder with superimposed episodes of activity. The characteristic histological appearances are those of a chronic aggressive hepatitis, and in untreated cases cirrhosis develops rapidly. Indeed it is present already at time of diagnosis in more than a third of the patients. Little is known of the pathogenesis, though the presence of tissue antibodies reacting with smooth muscle, nuclear, and mitochondrial antigens and the finding of cell-mediated immune responses to a liver-specific cell surface lipoprotein ${ }^{2}$ have suggested that autoimmunity is concerned. Evidence of disease in other organs of an autoimmune nature may also be present, Sjogren's syndrome and renal tubular acidosis being perhaps the most common; these are detectable in about $30 \%$ of cases according to a recent investigation of Golding $e t a l .^{3}$ The disordered immune responses may have a familial basis, for the first degree relatives 
have an increased incidence of tissue antibodies and abnormal immunoglobulin levels, ${ }^{4}$ and the presence of a genetic factor is also suggested by the finding of an increased frequency of the histocompatibility antigens $\mathrm{HL}-\mathrm{Al}$ and $\mathrm{HL}-\mathrm{A} 8$ in active chronic hepatitis as compared with a normal control population. ${ }^{5}$

The finding of hepatitis B antigen (HBAg) in the serum of some patients with active chronic hepatitis $-18 \%$ in a recent study $^{6}$ from Britain-has raised the possibility that not all cases have the same immunopathology. Clinical and serological differences between $\mathrm{HBAg}$-positive and HBAg-negative cases of this disease have been emphasized in a number of reports. Those carrying the antigen have been described as both younger ${ }^{7}$ and older. ${ }^{8}$ Gammaglobulin levels were said to be lower, ${ }^{89}$ tissue antibodies absent from the serum, ${ }^{8-10}$ biochemical abnormalities less severe, and prognosis better. ${ }^{8}$ Such differences, however, were not confirmed in the most recent study by Reed et al., ${ }^{6}$ who found that apart from an increased frequency of the antigen in males (up to $36 \%$ ) and in those born outside Britain the two groups seemed identical. Recognition of a male preponderance in the antigen-positive group is important. If it is ignored in statistical analyses of serum autoantibody patterns misleading results will be obtained, because the frequency of these autoantibodies is lower in males than in females. Reed and his colleagues ${ }^{6}$ found a lower frequency of antinuclear antibodies in the HBAgpositive than in the antigen-negative cases, but this was simply related to the greater number of males in the former group.

Another possibly distinct subgroup are those patients in whom the LE cell test is positive, who constitute some $15 \%$ in most series. However, an analysis of the patients taking part in the Mayo Clinic controlled trial of treatment for active chronic hepatitis showed that the only consistent difference to emerge was that these patients initially had more active disease than those in whom the test was negative. ${ }^{12}$ Their response to treatment was no different. In a further analysis of factors of possible prognostic importance Gitnick et al. ${ }^{13}$ found that the presence of lupus erythematosus cells (in 33\%), HBAg $(14 \%)$, and smooth muscle antibody $(86 \%)$ did not influence the prognosis, though this appeared to be worse in those patients with anticomplementary activity in their serum. Such anticomplementary activity (the ability of the serum to activate the complement system without added antigen) was detected while carrying out complement fixation tests for HBAg. Though it may indicate the presence of immune complexes, bacterial contamination of sera, other contaminants, or electrolyte abnormalities may have the same effect. Furthermore anticomplementary activity is not specific for a particular antigen-antibody system and so is not necessarily related to HBAg. Unfortunately, Gitnick and his colleagues did not carry out electronmicroscopic or further immunological studies to confirm that antigen-antibody complexes were present. Other workers, however, have described complexes containing HBAg on electron microscopy of sera from patients with antigenpositive active chronic hepatitis. ${ }^{14} 15$

Though there may be minor differences, most of the important clinical and pathological features of the disease are present in all the subgroups of active chronic hepatitis so far described, and it seems most likely that the chronic liver cell destruction is due to a common immunopathological process. The results of all the controlled trials which have been reported to date also show that the approach to treatment should be the same. Prednisone is effective both in controlling the activity of the disease and in reducing mortality. ${ }^{16-18}$ Treatment with azathioprine alone seems no better than placebo, but it is possible that its use in combination with prednisone may allow a lower dose of steroid to be used with a consequent reduction in steroid side effects. ${ }^{17}$

1 Doniach, D., Roitt, I. M., Walker, J. G., and Sherlock, S., Clinical and Experimental Immunology, 1966, 1, 237.

Miller, J., et al Lancet, $1972,2,296$

3 Golding, P. L., Smith, M. G. M., and Williams, R., American Fournal of Medicine, 1973, 55, 772.

Medicine, 1973, 55, 772.
Galbraith, R. M., et al., New England Fournal of Medicine, 1974, $290,63$. 5 Galbraith, R. M., et al., New England Fournal of Medicine

Reed, W. D., et al., Lancet, 1973, 2, 690 .

Bianchi, P., et al., Gastroenterology, 1972, 63, 482

Sherlock, S., Fox, R. A., Niazi, S. P., and Scheuer, P. J., Lancet, 1970, 1, 1243.

Bulkley, B. H., Heizer, W. D., Goldfinger, S. H., Isselbacher, K. J., and Shulman, N. R., Lancet, 1970, 2, 1323.

10 Cooksley, W. G. E., et al., Australian and New Zealand Fournal of Medicine, 1972, 2, 261.

11 Mackay, I. R., and Wood, I. J., Quarterly fournal of Medicine, 1962, 31, 485.

12 Soloway, R. D., Summerskill, W. H. J., Baggenstoss, A. H., and Schoenfield, L. J., Gastroenterology, 1972, 63, 458.

13 Gitnick, G. L., Summerskill, W. H. J., Soloway, R. D., Ritman, S., and Schoenfield, L. J., Archives of Internal Medicine, 1973, 213, 502.

${ }_{14}$ Almeida, June D., and Waterson, A. P., Lancet, 1969, 2, 983.

15 Reed, W. D., et al., Lancet, 1973, 2, 1347.

Cook, G. C., Mulligan, R., and Sherlock, S., Quarterly fournal of Medicine, $1971,40,159$.

17 Soloway, R. D., et al., Gastroenterology, 1972, 63, 820.

18 Murray-I yon, I. M., Stern, R. B., and Williams, R., Lancet, 1973, 1, 735

\section{Respiratory Complications of Obesity}

Overweight people often develop abnormalities in pulmonary function in the absence of primary lung disease, though they often develop chronic obstructive bronchitis too. The effects of obesity on pulmonary function vary widely in severity, and this does not necessarily depend on the degree of overweight. In most obese persons the pulmonary changes are trivial and are detectable only by pulmonary function measurements, but in others, especially those who develop hypoventilation, severe abnormalities may develop and death may occur from respiratory complications.

Oxygen consumption and carbon dioxide production are greater than normal in the obese both at rest and on exercise, ${ }^{1}$ implying that they have to ventilate more than usual to maintain normal arterial blood gas tensions. But the layers of fat on the chest wall and abdomen reduce the bellows action of the thoracic cage, the diaphragm is elevated, and the total work of breathing is increased, due mainly to reduced chest wall compliance. The functional residual capacity is low (because the expiratory reserve volume is much reduced) so that the resting end-expiratory position is lower than normal in the obese. This leads to low ventilation-perfusion ratios in the basal regions, more marked in the supine position. Nevertheless, in spite of the presence of hypoxaemia, most obese persons can maintain a normal level of alveolar ventilation and a normal arterial carbon dioxide tension. ${ }^{2}$

The association of obesity, episodic somnolence, hypoventilation, and cor pulmonale is often referred to as the Pickwickian syndrome, ${ }^{3}$ after the messenger Joe, "the fat and red-faced boy" described by Charles Dickins in The Pickwick Papers. This syndrome occurs in some $10 \%$ of obese subjects; in addition to hypoxaemia and abnormalities of thoracic mechanics there is alveolar hypoventilation and hypercapnia, and it is this finding that distinguishes the syndrome from the pulmonary consequences of simple obesity. The Pickwickian syndrome may occur in the non-obese, when it is usually associated with neurological abnormalities, ${ }^{4}$ but neurological disorders are not invariably present ${ }^{5}$ and in these circumstances the condition is usually called primary alveolar hypoventilation. 